\title{
Rheological Nonlinearity and Flow Instability in the Deforming Bed Mechanism of Ice Stream Motion
}

\author{
BARCLAY KAMB
}

\author{
Division of Geological and Planetary Sciences, California Institute of Technology, Pasadena
}

\begin{abstract}
Contrary to what has recently been assumed in modeling the proposed deforming bed mechanism for the rapid motion of Antarctic ice streams, the rheology of water saturated till is probably highly nonlinear, according to information from soil mechanics and preliminary experiments on till from the base of Ice Stream B. The equivalent flow law exponent $n$ is probably as high as -100 , and the nonlinearities of the shear stress and effective pressure dependences are closely linked. The high nonlinearity has important consequences for the deforming bed mechanism. A flow system operating by this mechanism can be unstable as a result of feedback from the generation of basal water by shear heating of basal till. The short-term feedback effect is analyzed for a perturbation in a model ice stream in which the basal meltwater is transported through a distributed system of narrow gap-conduits at the ice-till interface. Although the analysis is approximate and some of the system parameters are poorly known, the results suggest that the deforming bed mechanism is unstable for $n>-20$. The apparent lack of such an instability in the currently active ice streams implies that their motion is controlled not by the deforming bed mechanism but by some other as yet unidentified mechanism.
\end{abstract}

\section{INTRODUCTION}

The West Antarctic ice sheet is traversed by about a dozen ice streams $-50 \mathrm{~km}$ wide and $\sim 500 \mathrm{~km}$ long, in which the ice is moving at speeds up to $-800 \mathrm{~m} \mathrm{yr}^{-1}$, in sharp contrast to the motions of $\sim 10 \mathrm{~m} \mathrm{yr}^{-1}$ in the general mass of the ice sheet outside the ice streams [Bentley, 1987]. There is interest in these rapid motions as a phenomenon of glacier mechanics [Clarke, 1987a] and as a process that may be important in a possible collapse of the ice sheet, with worldwide consequences [Hughes, 1977, p. 44; Weertman and Birchfield, 1982; van der Veen, 1987, p. 8; Lingle and Brown, 1987, p. 279; Bindschadler, 1990].

To explain the rapid ice stream motions there has been developed, on the basis of seismic reflection data [Blankenship et al., 1987], a deforming bed model according to which the ice moves rapidly by deformation of a layer of soft, watersaturated till at its base [Alley et al., 1987a, 1987b; 1989; Alley, $1989 a, 1989 b$; MacAyeal, 1989]. From boreholes to the bottom of Ice Stream B, direct evidence of the basal till and of physical conditions suitable for its deformation has been obtained [Engelhardt et al., 1990; Kamb, 1990]. Glacier and ice sheet movement by soft-bed deformation, instead of by the normally considered mechanisms of ice deformation and basal sliding, has been advocated as an important new paradigm of glaciology [Boulton, 1986] and as the flow mechanism for large parts of the ice age North American and Fennoscandian ice sheets [Boulton and Jones, 1979; Boulton et al., 1985; Brown et al., 1987].

Crucial to the deforming bed model are the mechanical properties of the basal till, which relate the shear deformation of the till to the shear stress at the base of the ice and specify how this relation is influenced by basal water pressure [Alley et $a l ., 1987 b$, p. 8937]. In the modeling of the deforming bed mechanism that has been done to date, a linear or nearly linear rheology has been assumed. The present paper

Copyright 1991 by the American Geophysical Union.

Paper number 91JB00946. 0148-0227/91/91JB-00946\$05.00 undertakes to show that a highly nonlinear relation is much more likely and that such a relation has important consequences for the stability of ice stream motion if controlled by bed deformation.

\section{CONSTITUTIVE RELATION FOR TILL}

\section{Current View}

In the modeling to date of ice stream motion by the deforming bed mechanism, the till flow law relating shear strain rate $\dot{\gamma}$ to shear stress $\tau$ and effective pressure $\hat{P}=P_{\mathrm{I}}-P_{\mathrm{W}}$ (where $P_{\mathrm{I}}$ is overburden pressure and $P_{\mathrm{W}}$ is pore pressure of water) has been assumed to have the form

$$
\dot{\gamma}=C_{\tau}{ }^{n} / \hat{P}^{m}
$$

where $C$ is a constant (the "softness parameter") and where $n=1$ [Alley et al., 1987b; Alley, 1989b; MacAyeal, 1989] or $n=1.3$ [Alley et al., 1989, Figures 3 and 4]. Alley [1989b] and Alley et al. [1989] worked with several values of $m$ from 0 to 5, while MacAyeal [1989] did not include the effect of pore water pressure in his model. Lingle and Brown [1987, pp. 266 and 268] took $n=1$ and $m=1$ in a model that can be considered to be based on (1) if the assumed basal sliding law is interpreted as resulting from deformation of the postulated basal aquifer layer [Lingle and Brown, 1987, p. 251].

The assumed flow law was based on results of Boulton and Hindmarsh [1987] from field observation of the deformation of subglacial till near the terminus of an Icelandic glacier, Breidamerkurjokull. The data, seven triplets of values $(\dot{\gamma}, \tau$, $\hat{P}$ ), fitted a law of the form (1) with $n=1.3$ and $m=1.8$, thus showing only slight rheological nonlinearity. Boulton and Hindmarsh [1987, p. 9063] also fitted to the data a flow law of the form

$$
\dot{\gamma}=C\left(\tau-\tau_{f}\right)^{n} /(\hat{P})^{m} \quad\left(\tau \geq \tau_{f}\right)
$$

where $\tau_{f}$ is yield strength, given by

$$
{ }^{\tau_{f}}=c+\mu \hat{P}
$$


the constants $c$ and $\mu$ being the cohesion and internal friction; for $\tau<\tau, \dot{\gamma}=0$. They obtained $n=0.6, m=1.2, \mu=0.6$, and $c=0.04$ bar, with no improvement in goodness of fit (correlation coefficient) over the law of form (1). Since the nonlinearity represented by nonzero $\tau_{f}$ in (2) tends to be compensated by the "sublinear" $n<1$, only a slight nonlinearity is again indicated by these results.

Clarke [1987b, p. 9027] postulated for saturated till a law of type (2) $+(3)$ with $n=1$ (Bingham flow law), $m=0$, and $c$ a somewhat complex function of $\hat{P}$. For application to landslides, Iverson [1985, p. 148] proposed a three dimensional generalization of $(2)+(3)$, with $m=0$; fitting (2) to vertical profiles of flow velocity in four landslides gave $\tau_{f} \sim 0.4$ bar and $n$ ranging from 0 to 5 [Iverson, 1985, Figure 4; 1986, Figures 4 and 5]. (The velocity profiles were rather irregular, which prevented a close fitting of the flow law.)

\section{Evidence From Soil Mechanics}

The constitutive relation for till, as a granular material with a high content of clay-size particles, should be consistent with what is known about such materials in soil mechanics. In the geotechnical literature on the creep of clay-rich soils, much of the creep data are fitted reasonably well by the Singh-Mitchell creep equation [Singh and Mitchell, 1968; Borja and Kavazanjian, 1985] based on rate process theory [Mitchell et al., 1968; Feda, 1989]:

$$
\dot{\gamma}=\dot{\gamma}_{o}\left(t_{1} / t\right)^{s} \exp \left(\alpha \tau / \tau_{f}\right)
$$

where $t$ is time starting with $t=t_{1}$, at stress onset, and where $t_{1}$, $\dot{\gamma}_{0}, s$, and $\alpha$ are constants. The yield stress $\tau_{f}$ is given by (3), normally with $c=0$, and with $\mu$ dependent on the porosity of the soil. The relationship (4) is considered to apply for $\tau$ in the range $0.3 \tau_{f} \leq \tau \leq 0.9 \tau_{f}$ [Singh and Mitchell, 1968, p. 30], which is enough below the yield stress that the soil does not grossly fail and the strain does not increase to large values on the time scale of experimental tests. Thus typical values of $s$ are in the range $0.75 \leq s \leq 1$, so that (4) describes transient, decelerating creep. The parameter $a$ in (4) is typically in the range 3-7 for this type of creep [Mitchell et al., 1968, Figures 11 and 12; Singh and Mitchell, 1968, Figures 17 and 21; Borja and Kavazanjian, 1985, p. 294; Feda, 1989, Figure 3].

The till flow law needed in order to model the deforming bed mechanism must describe steady state creep at large strains, with the till at failure $(\tau=\tau$ ), rather than decelerating transient creep at $\tau$ well below failure, as (4) does. The strength at large strains, called the residual strength, has been studied for a variety of clay-rich soils by laboratory testing with the ring-shear apparatus and by quantitative evaluation of landslides [Bishop et al., 1971; Bolton, 1979, p. 255; Skempton, 1985; Maksimovic, 1989]. The flow law is, from the viewpoint of soil mechanics, the strain rate dependence of the residual strength. This has been investigated for clay-rich soils by Skempton [1985, p. 14], who finds that the residual strength $\tau_{r}$ increases with the shear rate, but only slightly. The dependence follows the form of (4), with $\tau$ replaced by $\tau_{r}$, and with $s=0$ (steady state). Solved for $\tau_{r}$ (4) gives the standard form for the strain rate dependence of the residual strength $\tau_{r}$ :

$$
\tau_{r}=\tau_{o}\left(1+a^{-1} \ln \left(\dot{\gamma} / \dot{\gamma}_{o}\right)\right) \quad\left(\dot{\gamma} \geq \dot{\gamma}_{o}\right)
$$

Here $\tau_{o}$, which replaces $\tau_{f}$ in (4), is the residual strength at a reference strain rate $\dot{\gamma}_{o}$ below which $\tau_{\mathrm{r}}$ becomes independent of $\dot{\gamma}$ and (5) no longer applies. (5) is given, in different symbols, by Feda [1989, equation (9)] and by Prapaharan et al. [1989, equation (10)]. The effective-pressure dependence of the creep strength in (5) is contained in the dependence of $\tau_{0}$ on $\hat{P}$ analogous to the dependence of $\tau_{f}$ on $\hat{P}$ in (3):

$$
\tau_{0}=c_{0}+\mu_{0} P
$$

normally with $c_{\mathrm{o}}=0[$ Feda, 1989, p. 670].

In ring-shear tests reaching the residual state the sample usually develops a narrow internal shear zone, and it is therefore standard practice to replace the ratio $\dot{\gamma} / \dot{\gamma}_{0}$ in (5) with $v / v_{0}$ where $v$ is slip rate across the shear zone and $v_{0}$ is a reference slip rate analogous to $\dot{\gamma}_{0^{\circ}}$

The form (5) (with $\gamma / \dot{\gamma}_{0} \rightarrow v / v_{0}$ ), accompanied by (6), is used in the geophysical literature [Tullis, 1988; Biegel et al., 1989; Scholz, 1990, Figures 2.18 and 2.22] to describe the shear rate dependence of the steady state frictional strength of fault gouge. Conventionally, a parameter $(a-b) / \mu_{0}$ is written in place of $\alpha^{-1}$ in (5). Gouge of course bears a relation to till in that both are granular materials produced at least in part by mechanical comminution.

Because of the form of (5), the dependence of residual strength on shear rate is commonly expressed in terms of the slope $S$ of the curve of $\tau_{r}$ plotted against $\log _{10} \dot{\gamma} ; S$ is usually given as the percentage increase of $\tau_{r}$ per decade (or "log cycle") increase of $\dot{\gamma}$. Thus

$$
S=100 \partial \ln \tau_{r} / \partial \log \dot{\gamma}
$$

Data given by Skempton [1985, p. 14] show $S=1.1-3.1 \%$ per decade, and from residual-strength tests reported by Bishop et al. [1971, p. 302], $S=1.9 \%$ per decade. From other tests on the strain rate dependence of soil strength not definitely at the residual limit, $S$ is commonly reported in the range 7-13\% per decade [Borja and Kavazanjian, 1985, Figure 8; Nakase and Kamei, 1986; Prapaharan et al., 1989, p. 618; O'Reilly et al., 1989, Figure 4].

A comparison of observed $S$ values with what has been assumed in modeling the deforming bed mechanism is obtained by finding the equivalent value of $n$ in (1), with $\tau \rightarrow \tau_{r}$; from (5) and (6),

$$
n=\partial \ln \dot{\gamma} / \partial \ln \tau_{r}=(100 \ln 10) / S=a \tau_{r} / \tau_{0} \approx a
$$

(The last step follows because $\tau_{\mathrm{r}} \approx \tau_{0}$ when the medium is deforming at failure.) Thus $S=13 \%$ per decade corresponds to $n=18$, and $S=2 \%$ per decade corresponds to the prodigious value $n \approx 115$. The extreme nonlinearity represents mechanical behavior close to perfect plasticity, for which $S=0$ or $n \rightarrow \infty$. It contrasts with the relatively mild nonlinearity in the transient creep law (4), for which $\alpha-3-7$ as noted earlier. The increase in sensitivity of strain rate to stress as $\tau \rightarrow \tau_{f}$ is a natural expectation [see Mitchell et al., 1968, Figure 11].

The mechanical properties of the till under the ice streams are doubtless not exactly the same as those of the clay-rich soils tested by Bishop [1971] and Skempton [1985]. Because of the sand and pebble content of the till [Engelhardt et al., 1990 , Figure 4], its behavior will probably be closer to perfect treiboplastic failure than is the case with the clay-rich soils tested, so that the equivalent $n$ value for the till flow law will probably be even higher than -100 .

In the relation (5) for the steady state strength of fault 
gouge, from experiments to date $a^{-1}$ is found to be a small quantity that increases gradually with the shear rate from about -0.007 at $v=0.3 \mathrm{~mm} \mathrm{~d}^{-1}$ to about +0.013 at $v=130 \mathrm{~m}$ $\mathrm{d}^{-1}$ [Blanpied et al., 1987, Figure 3]. Negative $a^{-1}$, which is found for $v<1.3 \mathrm{~m} \mathrm{~d}^{-1}$ and is called "velocity weakening," constitutes a more extreme rheological nonlinearity than is represented by small but pasitive $a^{-1}$. The extreme nonlinearity in the constitutive relation of gouge cannot be expected to apply directly to till, for one reason because the stress levels in the gouge experiments ( $\tau \geq 50$ bar) are much higher than in the till under the ice streams ( $\tau \leq 0.5$ bar). But the gouge behavior reinforces the view that the dependence of residual strength on shear rate is very slight (i.e., $\alpha$ is large) for such materials, and they can even show velocity weakening. This has its counterpart in the behavior of soils: Lambe and Whitman [1969, p. 314] have noted an ambivalence between slight strengthening and slight weakening in the effect of shear rate on soil strength.

\section{Tests on Till From Ice Stream B}

Freshly cored till from the base of Ice Stream B [Engelhardt et al., 1990, p. 59] was tested by the direct-shear method [Bolton, 1979, p. 69] in a test cell of diameter $2.5 \mathrm{~cm}$, operating in the creep mode (applied shear load held constant during the test; shear displacement recorded every $15 \mathrm{~s}$ ). The material tested was packed into the test cell to a total depth of $3 \mathrm{~cm}$, and rare coarse clasts encountered in the packing process were removed. The removed clasts, $>\sim 10 \mathrm{~mm}$ in size, constituted less than $2 \%$ of the sample volume. Tests were carried out in the open air and under a nominal normal stress of 0.017 bar. The pore pressure was not controlled, but because of the very low hydraulic conductivity of the till [Engelhardt et al., 1990, p. 248] and the short test duration the tests were essentially undrained and therefore should reproduce the mechanical properties under in situ conditions, independent of the normal stress or external availability of pore water [Bolton, 1979, p. 94; Lambe and Whitman, 1969, p. 440].

The most informative results, from repeated tests on a single sample, are shown in Figure 1. Tests were done alternately at $\boldsymbol{\tau}=\mathbf{0 . 0 1 8}$ bar and $\mathbf{0 . 0 2 2}$ bar. At the lower shear stress all tests resulted in decelerating creep; the open circles plotted are the initial shear displacement rates (averaged over the first $15 \mathrm{~s}$ of the test), and the arrows pointing downward indicate rates decreasing steadily to near unobservability in 1 or $2 \mathrm{~min}$. At the higher stress all tests gave rapid shear displacement rates and accelerating creep leading quickly to "catastrophic" failure (arbitrarily large displacement, which was restrained by stops); the open circles plotted have the same meaning as before, and the small arrows pointing upward indicate accelerating slip rates leading to catastrophic failure. The large, open, arrows pointing upward are lower limit values for initial strain rates in tests in which the creep acceleration was so rapid that the moving part of the test cell hit the stops before the end of the first $15-\mathrm{s}$ interval. In one experiment at $\tau=0.022$ bar there was a short early stage of decelerating creep, followed by accelerating creep and failure, as arrows in Figure 1 indicate.

The results in Figure 1 show that in these tests the till behaved very much like a plastic material with yield stress of about 0.02 bar, reproducibly bracketed between the two stress levels tested. Decelerating creep was extensively observed at stresses below catastrophic yield, as in Figure 1; it corresponds

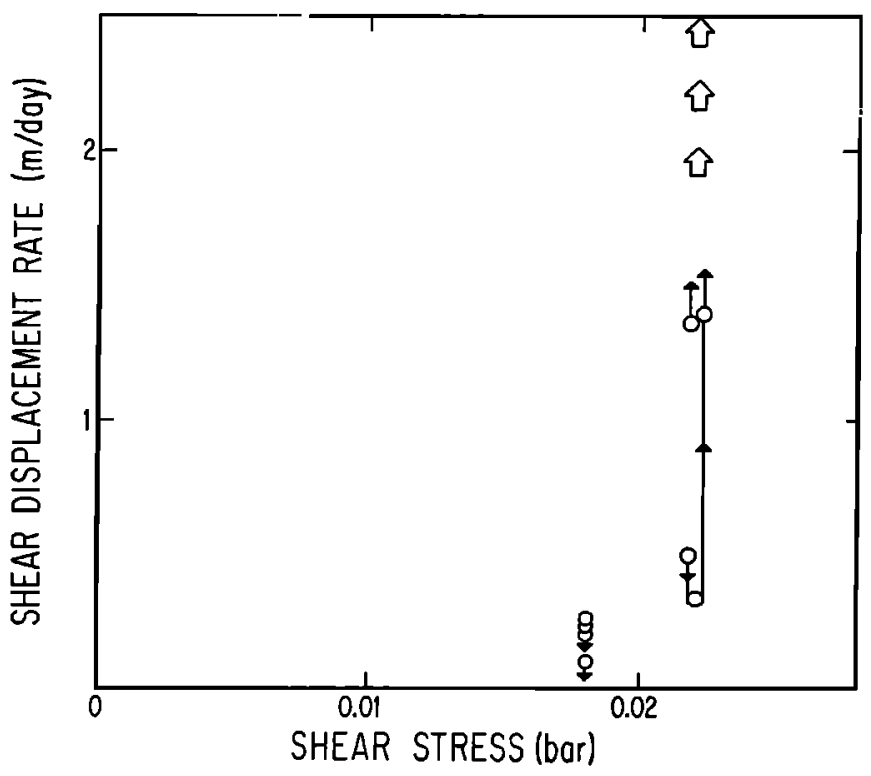

Fig. 1. Direct shear test data (shear displacement rate versus shear stress) for till from the base of Ice Stream B at Upstream B. Data are for a single specimen from a depth of $10 \mathrm{~cm}$ below the top of the till. The specimen was tested repeatedly, at shear stresses of 0.018 bar and 0.022 bar, alternately. Open circles are the average shear rate during the first $15 \mathrm{~s}$ after stress application, and small arrows indicate the direction of transient change of the shear rate. In the case where arrows point downward, the shear displacement rate decreased to < -1 $\mathrm{mm} \mathrm{d}^{-1}$ in 2-3 min.; in case where arrows point upward, the rate increased to $>-2 \mathrm{~m} \mathrm{~d}^{-1}$ in $15 \mathrm{~s}$ or less. Large, open arrows are lower limits for the shear rate in tests in which the initial shear rate was so high that the moving part of the shear box hit the stops before the end of the first $15 \mathrm{~s}$.

qualitatively to the expectations of (4). Figure 1 cannot be used to fix an equivalent $n$ value because steady state creep rates were not achieved, either in the decelerating creep below the yield stress or in the accelerating creep above; however, from the constraints that the data provide it is clear that $n$ would have to be very large.

A second till sample was later tested in a larger direct-shear cell (diameter $6.35 \mathrm{~cm}$ ) operating in the displacementcontrolled mode (specimen sheared at a controlled slip rate, shear force recorded as a function of shear displacement). Figure 2 shows the results of 16 tests of this type, done at low, intermediate, and high shear rates as indicated in the figure caption. The range in shear displacement rates, from $0.09 \mathrm{~m}$ $\mathrm{d}^{-1}$ to $5.2 \mathrm{~m} \mathrm{~d}^{-1}$, brackets the basal motion of Ice Stream B at Upstream $B, 1.2 \mathrm{~m} \mathrm{~d}^{-1}$. In all tests an approximately steady strength was reached toward the end. The strength varies by about $\pm 6 \%$ from test to test. The strengths for slow, intermediate, and fast shear fall within the same scatter and are not clearly resolved from one another. The mean strength for the slow tests is $1.6 \pm 0.1 \mathrm{kPa}$ and for the fast tests $1.7 \pm 0.1$ $\mathrm{kPa}$. The indicated value of $S$ is $3 \pm 3 \%$ per decade. The equivalent $n$ value from (8) is 75 , but in relation to the standard deviation, $S$ does not differ significantly from 0 (or $n$ from $\bullet$ ).

The observed strengths in the second series of tests are reasonably compatible with the 0.02 bar strength from the first series. (The second sample was tested 8 months later, having been stored at $+1^{\circ} \mathrm{C}$ in packaging intended to minimize water loss by evaporation.) A later test was run on a sample from which all grains larger than $0.4 \mathrm{~mm}, 20 \%$ by volume of the 


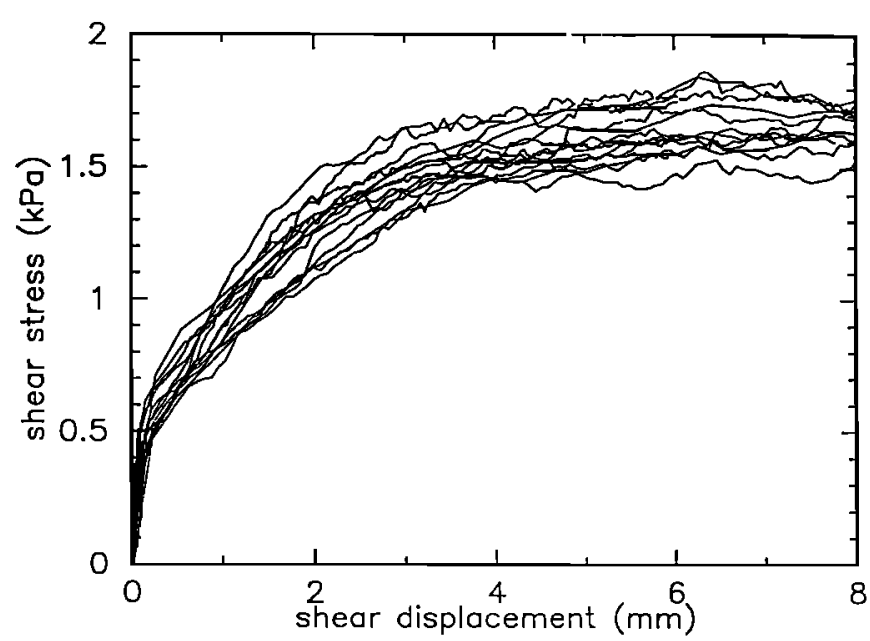

Fig. 2. Results of 16 controlled-strain direct shear tests on second till sample from the base of lce Stream B, at three different shear rates. Shear stress is plotted against shear displacement in each test. Three tests were carried out at a shear displacement rate of $0.09 \mathrm{~m} \mathrm{~d}^{-1}, 10$ tests at a rate of $0.86 \mathrm{~m} \mathrm{~d}^{-1}$, and three at $5.2 \mathrm{~m} \mathrm{~d}^{-1}$. Tests at the slowest rate give data curves of the most "jittery" character, and tests at the fastest rate give the least "jittery" curves, because the data sampling rate was the same for all tests. Data courtesy of $H$. Engelhardt.

original material, were removed; the strength was 0.018 bar, essentially unchanged from that of the original material. This makes it quite unlikely that removal of only the coarsest clasts ( $>\sim 10 \mathrm{~mm}$ ), constituting less than $2 \%$ by volume of the till as sampled, had more than a small effect on the strength. Drying the till and then reconstituting it back to the original water content ( $25 \%$ by weight) also had little effect on the strength. Since the till was probably undergoing shear deformation in situ, before sampling, and since it was necessarily deformed somewhat in the sampling process, the further disturbance involved in packing it into the test cell is unlikely to have altered its strength greatly. Disturbance of clay particle alignment that might be present in the residual state in situ would increase the strength over that in situ.

The tests cannot be considered to give a determination of $S$ for the residual strength, because the total shear displacement was only $8 \mathrm{~mm}$ in the tests. On the basis of the earlier discussion, $\boldsymbol{S}$ is expected to be reduced in the residual state.

The features of mechanical behavior observed in the tests are qualitatively similar to those found in geotechnical testing of clay-rich soils at large strains, as described earlier. They are very different from what would be expected on the basis of flow law (1) with the parameters found by Boulton and Hindmarsh [1987].

\section{Dependence on Effective Pressure}

Whereas in flow law (1) the dependence of $\dot{\gamma}$ on $\tau$ is independent of the dependence on $\hat{P}$, so that the two can have very different nonlinearities, in $(5)+(6)$ the two are coupled together. The $\hat{P}$ dependence in (5) can be compared with (1) by finding the equivalent value of $m$, from differentiation of (5) and (6):

$$
m=-\left(\frac{\partial \ln \dot{\gamma}}{\partial \ln \hat{P}}\right)_{\tau_{r}}=\alpha \frac{{ }^{\tau_{\mathrm{r}}}}{\tau_{\mathrm{o}}} \cdot \frac{\mu_{\mathrm{o}} \hat{P}}{c_{\mathrm{o}}+\mu_{\mathrm{o}} \hat{P}} \approx a \frac{\tau_{\mathrm{r}}}{\tau_{\mathrm{o}}} \approx \alpha
$$

The first approximate equality follows in case $c_{0}=0$ or is small compared to $\mu_{0} \hat{P}$, as expected for an uncemented material [Bolton, 1979, p. 23]. Thus for flow law (5)+(6) the equivalent $n$ from (8) is approximately the same as the equivalent $m$ from (9). In view of the preceding discussion, suggesting $a-100$ for till or till-like soil, the current choices $m=0,1,2$, or even 5 in modeling ice stream motion (as cited at the outset) give a greatly inadequate representation of the sensitivity of strain rate to effective pressure.

As long as the approximation $c_{0} \kappa_{\mathrm{o}_{\mathrm{o}}} P$ in (9) holds, the pressure sensitivity as measured by $m$ does not depend, ostensibly, on the internal friction $\mu_{0}$, which seems contrary to intuition. However, the viewpoint of gouge mechanics, which takes $\alpha=\mu_{0} /(a-b)$ as noted earlier and considers $(a-b)$ as a fundamental parameter, implies that a (and thus the equivalent $m$ ) does depend on the friction.

\section{ICE STREAM FLOW STABILITY}

If the till flow law is highly nonlinear, as the foregoing discussion suggests, there are important consequences for the deforming bed mechanism of ice stream motion. The highly nonlinear response to shear stress will lead to glacier flow behavior of types akin to those discussed by Nye [1951] for ice deforming as a perfectly plastic substance, but with the significant complication that the till yield stress is a function of the effective pressure. The highly nonlinear reciprocal dependence of flow on effective pressure, which according to $(5)+(6)$ is directly linked to the nonlinear shear-stress dependence, will couple the flow sensitively to the basal water pressure. In particular, there is a basal-water-pressure feedback mechanism that for sufficiently nonlinear dependence results in instability of the flow system. This striking consequence of flow law nonlinearity is now considered. The instability is entirely separate from the marine ice sheet instability that has been much discussed in connection with the West Antarctic Ice Sheet [e.g., Thomas et al., 1979; van der Veen, 1987].

\section{Basal-Water-Pressure Feedback Mechanism}

In a glacier or ice stream moving by the deforming bed mechanism, the deformability of the subglacial till is made possible by high pore water pressure [Alley et al., 1987a; Engelhardt et al., 1990]. For an Antarctic ice stream, in which the ice is below freezing except at its base, the source of the pore water is melting of basal ice, which is due to the frictional heat generated by till deformation, plus the geothermal heat flux, less the heat flux conducted upward within the subfreezing ice mass. The basal water pressure must adjust itself so that in a steady state the water produced by basal melting does not accumulate progressively but is conducted away, ultimately to the ocean at the grounding line, through some type of water conduit system. In such a flow system there can be a positive feedback mechanism for basal-waterpressure perturbations. If the water pressure increases, so that the till pore pressure increases, the till deformation rate will increase; this will increase the basal melting rate, which will result in a further increase in basal water pressure, unless the increased pressure causes the conduits to enlarge sufficiently. Depending on its physical parameters, the system can be either stable or unstable in relation to such water pressure perturbations.

This basic type of feedback effect and the resulting stability issue for the deforming bed mechanism has been noted but 
not analyzed by Alley et al. [1987b, p. 8938]. It also arises for the basal sliding mechanism of ice stream or polar glacier motion, as has been discussed from various different points of view, mainly in relation to glacier or ice sheet surging, by Weertman [1969], Budd [1975], Budd and McInnes [1979], Weertman and Birchfield [1982]; and Oerlemans and van der Veen [1984, pp. 107 and 189].

In this paper I investigate the immediate instability that can arise from the basal-water-pressure feedback mechanism in a simple ice stream flow model based on the deforming bed mechanism. By "immediate" I mean that which is an immediate consequence of the feedback, leaving out of consideration the effects of longer-term responses such as changes in ice thickness, till thickness, longitudinal stress gradient, or temperature distribution in the ice. These longerterm responses tend to provide ultimate damping effects on the immediate instability, as suggested by model calculations of Oerlemans and van der Veen [1984, p. 191].

\section{Flow System with Feedback}

Consider a laterally uniform, constant-width ice stream that can be treated as a one-dimensional flow system with longitudinal coordinate $x$, increasing downstream. The ice moves by shear of a basal till layer with flow law (5)+(6), whose basal-water-pressure dependence can for present purposes be written in differential form from (9) as

$$
\partial v / \partial\left(P_{\mathrm{I}}-P_{\mathrm{W}}\right)=-n v / \hat{P}
$$

$v(x)$ is the basal ice velocity, equal to $\gamma h$, where the (assumed uniformly shearing) till thickness is $h$, which drops out of (10) because of the logarithmic form of $(9) . P_{\mathrm{W}}(x)$ is the basal water pressure, assumed equal to the till pore pressure, $P_{\mathrm{I}}(x)$ is the ice overburden pressure, and $\hat{P}=P_{\mathrm{I}}-P_{\mathrm{W}}$ is the effective pressure. In view of (8), $n$ is written in place of $\alpha$ in (10), because $\alpha$ is so commonly used in the glaciological literature for ice surface slope. We consider a perturbation $\Delta P_{\mathrm{W}}(x)$ in basal water pressure, which results, according to (10), in an ice velocity response

$$
\Delta v=(n v / \hat{P}) \Delta P_{\mathrm{W}}
$$

This response is assumed for simplicity to be immediate, which neglects the time delay in equilibration of the till pore pressure to the perturbation in basal water pressure. In obtaining (11) from (10) it is assumed that over the time period considered, in the immediate response following the perturbation $\Delta P_{\mathrm{W}}(x)$, there is insufficient time for appreciable readjustment of the ice thickness (hence $P_{\mathrm{I}}$ ), till thickness $h$, or basal shear stress $\tau_{\mathrm{B}} \approx \tau_{\mathrm{r}}$, so that the velocity perturbation $\Delta v$ is entirely the result of the pressure perturbation $\Delta P_{\mathrm{W}}$.

A change in $v$ will result in a change in basal melting rate $\Delta \dot{M}$ given by

$$
\Delta \dot{M}=\tau_{\mathrm{B}} \Delta v / H
$$

where $H$ is the latent heat of melting per unit volume of ice $(H=0.31 \mathrm{G} \mathrm{Pa})$.

The effect of $\Delta \dot{M}(x)$ on the pressure perturbation $\Delta P_{\mathrm{W}}(x)$ depends on the nature of the conduit system through which the basal meltwater is conducted along the ice stream to the ungrounding line. Because little is known for a fact about this conduit system, it is necessary to make a heuristic assumption in order to proceed. Candidate model conduit systems that have been considered theoretically are the ice tunnel model [Röthlisberger, 1972; Bindschadler, 1983], the till channel or tunnel valley model [Boulton and Hindmarsh, 1987, p. 9077 ; Alley, 1989a, p. 112], the subglacial aquifer model [Lingle and Brown, 1987; Shoemaker, 1986], the water film model [Weertman, 1972; Weertman and Birchfield, 1982], and the linked cavity model [Humphrey, 1987; Kamb, 1987; Lliboutry, 1987]. Applied to Ice Stream B, the tunnel model appears to be ruled out because it gives at Upstream $B$ an effective pressure $\hat{P}=4$ bars [Bindschadler, 1983, p. 10], which is much larger than the observed effective pressures of -0.2 to 1.5 bar [Engelhardt et al., 1990, p. 248; Kamb, 1990, p. 10]. Theoretical arguments against applicability of the ice tunnel model, the till channel model, and the subglacial aquifer model have been given by Alley [1989a], who favors a water film model with a nonuniform film of spatially varying thickness. Such a model seems to me fundamentally similar to a linked cavity model. I will here assume that the water conduit system under the model ice stream is of this general type, and I will represent it in a simplified form similar to that used by Alley [1989a, p. 115; 1989b, p. 119].

I thus make the heuristic assumption that there is a discontinuously present water layer of thickness $d$ in a gap between the base of the ice and the top of the till, distributed in an interconnected manner over an areal fraction $\phi<1$ of the glacier sole. The interconnected water layer forms throughgoing conduits in which water can be transported along the base of the ice, at a local water pressure $P_{W}(x)$. The icetill interface in places where the water-filled gap is absent supports a higher normal stress in the ice, so that the average overburden pressure $P_{\mathrm{I}}>P_{\mathrm{W}}$ is supported. Field evidence from two independent experiments at Upstream B suggests that $d$ is about $1 \mathrm{~mm}$ (H. Engelhardt and B. Kamb, unpublished data, 1990), and a thickness of $4 \mathrm{~mm}$ at Upstream B was calculated theoretically by Alley et al. [1989, Figure 2]. The water layer conduit system provides water storage at the bed in the amount $W=\phi d$ per unit area of the bed. In both the water film and linked cavity models, both $\phi$ and $d$ are decreasing functions of $\hat{P}$. For the former this is shown by Alley [1989a, equation (17)] and Alley [1989b, equation (3)], and for the latter by Kamb [1987, equations (4), (5), (8), (10), (17), (24), and Figures 7-10], if we equate $d$ with the average gap width over the area of ice-bed separation (fractional area ф). I therefore make here the heuristic assumption that the water storage $W$ varies with $P$ as

$$
W \sim c / \hat{P}^{q}
$$

which has the expected divergence as $\hat{P} \rightarrow 0$ and the ice stream goes afloat. The parameter $q$ is a constant and $c$ may vary with $x$. The differential response to a small perturbation is then

$$
\Delta W \sim(q W / \hat{P}) \Delta P_{\mathrm{W}}=\mu \Delta P_{\mathrm{W}} / \rho g
$$

The conduit response parameter $\mu=\rho g q W / \hat{P}$, where $\rho$ is the density of water, is introduced for later convenience. The water storage adjustment to pressure change in (14) is for simplicity assumed to be instantaneous, although in reality some delay in the response must be involved.

To evaluate the effect of $\Delta \dot{M}$ on $\Delta P_{\mathrm{W}}$, we also need to be able to calculate the transport of water by the conduit system. 
Because the water flow velocities and conduit dimensions are small (measured transport velocity is $7 \mathrm{~mm} \mathrm{~s}^{-1}$ at Upstream B: H. Engelhardt, unpublished data, 1990), it is reasonable to assume a linear relation between the water transport flux (per unit width of the ice stream) and the water pressure gradient:

$$
\text { flux per unit width }=\kappa \partial P_{W} / \partial x
$$

where $\kappa$ is the effective hydraulic conductivity of the basal water system. In writing (15) it is assumed for simplicity that the bed is level, as it is under Ice Stream B to a reasonable approximation for $100 \mathrm{~km}$ upstream and downstream from Upstream B [Shabtaie et al., 1987, Figure 3; Shabtaie and Bentley, 1988, Figure 2]. The results do not depend on this simplifying assumption, however. In the water layer conduit model the conductivity $\boldsymbol{k}$ is given by

$$
\kappa=\phi d^{3} / 12 \eta
$$

where $\eta$ is the viscosity of water [see, for example, Alley's [1989a] equation (25) with the correction $q \rightarrow q / f$ in his notation]. In (16) the appearance of $\phi$ as a simple factor represents a conduit system with minimal conduit constriction consistent with restriction of the conduit gap to an areal fraction $\phi$ of the ice-till interface. The differential variation of $i c$ under a perturbation $\Delta W$ is thus

$$
\Delta \mathrm{k}=(3 \mathrm{k} / W) \dot{\Delta} W
$$

if for simplicity $\phi$ is assumed not to vary as the conduit thickness $d$ adjusts. (Justification for this simplification as a reasonable approximation can be found in the logarithmic dependence of $\phi$ on $d$ given in equation (3) of Alley [1989b]. The alternative simplification $d=$ constant would lead to removal of the factor 3 in (17), and a full development would give a response intermediate between these two cases.)

The pressure adjustment $\Delta P_{\mathrm{W}}$ to a change in basal melting rate $\Delta M$ is determined by the water continuity condition, based on (15):

$$
\begin{gathered}
\frac{\partial \Delta W}{\partial t}=\Delta \dot{M}+\frac{\partial}{\partial x} \Delta\left(\kappa \frac{\partial P_{\mathrm{W}}}{\partial x}\right)=\dot{\Delta M}+ \\
+\frac{\partial P_{W}}{\partial x} \frac{\partial}{\partial x}\left(\frac{3 \kappa}{W} \Delta W\right)+\frac{\partial \kappa}{\partial x} \frac{\partial \Delta P_{W}}{\delta x}+\kappa \frac{\partial^{2} \Delta P_{W}}{\partial x^{2}}
\end{gathered}
$$

in which the perturbation operation $\Delta$ is expanded for an infinitesimal perturbation, (17) is introduced, and the assumption $\partial^{2} P_{\mathrm{w}} / \partial x^{2}=0$ is made for a reason given below.

On the basis of (14) we can make the following expansion to evaluate the first term on the right side of (24):

$$
\begin{gathered}
\frac{\partial}{\partial x}\left(\frac{\kappa}{W} \Delta W\right)=\frac{\partial}{\partial x}\left(\frac{q \kappa}{\hat{P}} \Delta P_{W}\right)= \\
\frac{q}{\hat{P}}\left(\frac{\partial \kappa}{\partial x}-\frac{\kappa}{\hat{P}} \frac{\partial \hat{P}}{\partial x}\right) \Delta P_{W}+\frac{q \kappa}{\hat{P}} \frac{\partial \Delta P_{W}}{\partial x}
\end{gathered}
$$

The derivative $\partial \hat{P} / \partial x$ in (19) can be obtained from (10):

$$
\partial \hat{P} / \partial x=-(\hat{P} / n v) \partial v / \partial x
$$

The longitudinal strain rate $\partial v / \partial x$ could be taken from observation, but it seems more appropriate for the model treatment here to assume

$$
\partial v / \partial x=v / L
$$

The accuracy of (21) is not crucial, because the $n$ in the denominator in (20) tends to suppress the contribution from this term.

The quantities $W$ and $k$ and the derivatives $\partial k / \partial x$ and $\partial P_{\mathrm{W}} / \partial x$ that appear on the right side of (18) and (19) are to be evaluated for the datum state, from which the perturbations $\Delta P_{\mathrm{W}}$ and $\Delta W$ depart. Because $P_{\mathrm{W}}$ is observed to be close to $P_{\mathrm{I}}$ in Ice Stream B [Engelhardt et al., 1990, p. 248], we assume that in the datum state the hydraulic gradient is the same as the slope $B$ of the hydraulic grade line for ice flotation ( 0.9 times the surface slope if the bed is level):

$$
\partial P_{\mathrm{W}} / \partial x=-\rho g \beta
$$

For simplicity, $B$ is taken to be constant, so $\partial^{2} P_{W} / \partial x^{2}=0$ as stated above. The effective conductivity $x$ is that which provides the required flow of basal meltwater in the datum state:

$$
\kappa \rho g B=\int_{0}^{x} \dot{M}(x) d x-\overline{v \tau}_{\mathrm{B}} L / H
$$

where $\overline{v \tau}_{B}$ is the average of the product $v \tau_{B}$ over the ice stream, of effective length $L$, above the point $x$. The conductivity in the datum state must increase downstream so as to accommodate the basal meltwater generated locally:

$$
\rho g B \partial \kappa / \partial x=\dot{M} \approx \tau_{\mathrm{B}} v / H
$$

In writing (23) and (24) we assume for simplicity that the geothermal heat flux is approximately in balance with the upward heat conduction in the basal ice, so that the basal melting is due to basal till deformation. Error in this assumption could be corrected by applying correction factors to the products $\nu \tau_{B}$ and $\bar{\nu}_{B}$. In what follows we use $\psi=\bar{v} \bar{\tau}_{\mathrm{B}} / \nu \tau_{\mathrm{B}}$ and can incorporate the correction factors in $\psi$.

When (19) is introduced into (18) and substitutions from (11), (12), (14), (20), (21), (22), (23), and (24) are made, the continuity equation (18) becomes

$$
\frac{\partial \Delta P_{\mathrm{W}}}{\partial t}=D \Delta P_{\mathrm{W}}-E \frac{\partial \Delta P_{\mathrm{W}}}{\partial x}+F \frac{\partial^{2} \Delta P_{\mathrm{W}}}{\partial x^{2}}
$$

where

$$
\begin{gathered}
D=\frac{v \tau_{\mathrm{B}}}{H W}\left(\frac{n}{q}-1-\frac{\Psi}{n}\right) \\
E=\frac{v \tau_{\mathrm{B}}}{H}\left(\frac{3 L \Psi}{W}-\frac{1}{B \mu}\right) \\
F=\frac{v \tau_{\mathrm{B}} L \Psi}{H \mathrm{~B} \mu}
\end{gathered}
$$

An exact solution of (25) is available if the coefficients $D$, $E$, and $F$ are constant. A solution of the form

$$
\Delta P_{\mathrm{W}}=\Re a \exp [(2 \pi i x / \lambda)+\sigma t]
$$

(where $\$$ designates the real part) satisfies (25) if

$$
\sigma=D-2 \pi i E / \lambda-4 \pi^{2} F / \lambda^{2}
$$


It represents a spatially sinusoidal perturbation, as is commonly assumed in stability problems of this type. From (29) the time development of the perturbation is

$$
\Delta P_{\mathrm{W}}=a \exp \approx \sigma t \cos 2 \pi(x-E t) / \lambda
$$

If $\Re \sigma>0$, the perturbation grows exponentially and the system is unstable. The instability condition is thus

$$
\tilde{\boldsymbol{N} \sigma}=D-\frac{4 \pi^{2}}{\lambda^{2}} F=\frac{\nu \tau_{\mathrm{B}}}{H W}\left(\frac{n-U}{q}-1-\frac{\psi}{n}\right)>0
$$

where

$$
U=\frac{4 \pi^{2} \psi L \hat{P}}{\lambda^{2} B \rho g}
$$

The above results are only approximate because $D, E$, and $F$ in (25) vary (slowly) with $x$ as a result of the longitudinal increase in basal water flux in the datum state. The effect of the $x$ variation of the coefficients on the solutions of $(25)$ is considered in the Appendix; although there is a definite effect, it does not alter the basic conclusions reached above on the basis of the solution for constant coefficients.

Evaluated for Ice Stream B at Upstream B, with parameter values $B \sim 0.1^{\circ}, L \sim 100 \mathrm{~km}, \hat{P} \sim 1$ bar, $W \sim 1 \mathrm{~mm}$, $\tau_{\mathrm{B}}-0.2$ bar, $\nu-400 \mathrm{~m} \mathrm{yr}^{-1}, \Psi-0.5$, for a perturbation wavelength $\lambda-30 \mathrm{~km}$, (33) gives $U \sim 13$, and from (32) we obtain

$$
\Re \sigma=(14 \text { days })^{-1}\left(\frac{n-13}{q}-1\right)
$$

The term $-\psi / n$ in (32) is neglected in (34) because we expect $n$ to be large. Thus we conclude that if $n>13+q$, the system is unstable. The value of $U(=13$ in (34)) is inversely proportional to the square of the perturbation wavelength, $\lambda^{2}$, as (33) indicates; thus for $\lambda$ longer than $30 \mathrm{~km}$, the instability sets in for smaller flow nonlinearity $n$. For large $\lambda$, with $U \rightarrow 0$, the system is unstable for $n>q$.

There is no observational information on the value of the parameter $q$, but it can be derived theoretically. In the case of the linked-step-cavity model [Kamb, 1987], an analysis for laminar water flow, analogous to the derivation of equation (38a) of Kamb [1987] from equation (2) (for turbulent flow) in the same reference, yields $q=1$. For the water film model of Alley [1989a, b], one can obtain from equation (17) of Alley [1989a] and equation (3) of Alley [1989b] the result $q=1+10 \phi \ln 10$ applicable to the differential relation (14) of the present paper; for $\phi \sim 0.5$, this gives $q \sim 12$. In empirical sliding laws of a form like (1), $m$ appears mostly in the range 0-2 [Bentley, 1987, p. 8855], and one might be tempted, with a leap of imagination, to surmise on this remote basis that $q-m$. Within the wide foregoing range of constraints on $q$, a reasonably conservative conclusion is that the deforming bed system is unstable for $n>-20$ for perturbations of $30 \mathrm{~km}$ wavelength or $n>-5$ for $100 \mathrm{~km}$ wavelength.

From (31), the time scale of the instability (or of a stable response) is $|\Re \sigma|^{-1}$, which, from (32), is scaled by the timedimensional factor $H W / v \tau_{\mathrm{B}}$, equal to the time required to generate by basal melting enough water to replace the basal water storage in the datum state. For the parameter values assumed, $\left|* \sigma^{-1}\right|^{-1}$ is 14 days divided by the absolute value of the quantity in the final parenthesis in (34). This time scale is extremely short in relation to typical glacier adjustment time scales of years, and the treatment of the instability as "immediate" in the sense discussed at the outset is thus justified. The time scale of days is of the same order as that of glacier minisurges, which occur by adjustments in the basal water system [Kamb and Engelhardt, 1987].

The perturbation (31) moves as a wave with speed $E$ given by (27), which is 3 times the mean speed of water flow in the basal conduit system. For the parameters used (for which the second term on the right in (27) is negligible), $E / 3$ is $4 \mathrm{~cm} \mathrm{~s}^{-1}$; for $W=2.4 \mathrm{~mm}, E / 3$ is $1.8 \mathrm{~cm} \mathrm{~s}^{-1}$ and is equal to the transport speed implicit in $(15)+(16)+(22)$, with $\phi=0.5$. This speed is of the same order of magnitude as the water transport speed $0.7 \mathrm{~cm} \mathrm{~s}^{-1}$ measured by injection of salt-water in the basal water system of Ice Stream B (H. Engelhardt, unpublished data, 1990). $E$ is the speed of kinematic waves in a conduit system of the type modeled. Such waves are an inherent feature of the conduit system, independent of the ice stream flow instability under examination in this paper.

\section{Discussion AND CONCLUSIONS}

The results of the last section indicate that above a certain degree of nonlinearity in the till flow law the deforming bed mechanism of ice stream motion is unstable, because of feedback from the generation of basal meltwater by shear heating in the basal till. The instability is somewhat akin to creep instability by shear heating [Clarke et al., 1977; Oerlemans and van der Veen, 1984, p. 96; Hutter, 1983, pp. 160-179], but the feedback mechanisms are quite different in the two instabilities.

The type of flow law nonlinearity that affects the deforming bed instability considered here is nonlinearity in the inverse dependence of shear strain rate or basal slip rate on effective pressure at fixed shear stress. This nonlinearity is linked by the form of the applicable flow law (5) to the nonlinearity in the dependence on shear stress; both have the same effective exponent $n$, as discussed earlier.

The deforming bed instability depends heavily on the relationship (13) that specifies the response sensitivity of the basal conduit system to changes in the basal water pressure. The assumed relation (13) is valid, with $q=1$, for a linked cavity model of the basal water conduit system [Kamb, 1987], and is valid in its differential form (14) for a water film model [Alley, 1989a], with $q \sim 12$. The relationship gives only the final, steady state response of water storage to effective pressure, omitting the time-varying transient response by which the adjustment from the initial state to the final response proceeds once a perturbation has been imposed. To this extent, and also because of neglect of the transient delay in the equilibration of basal water pressure with till pore pressure, the time dependence of the perturbation given by (31) is incomplete. For an ice tunnel conduit model [Röthlisberger, 1972], the steady state relationship between $W$ and $\hat{P}$ is like (13) but with negative $q$ (for laminar water flow, $q=-3$ ), and there is the further complication that the steady state $W$ decreases with the water pressure gradient as $B^{-2}$. Leaving aside the effect of the latter complication, the effect of negative $q$ in the relation (32) is to make the system unstable against short wavelength perturbations in the case of small $n$, and stable for large $n$. However, it is not certain that the steady state would be reached, at least until after a period of oscillation, because the initial response of a tunnel to increased 
water pressure or to increased $B$ is to enlarge, which is a response in the opposite direction from the steady state response. These complications are not encountered in the foregoing treatment because, for reasons given earlier, a water layer conduit model was assumed to be appropriate.

Although the treatment does not include the ice-dynamicsmediated adjustments in ice thickness, ice temperature distribution, and ice flow velocity that would follow the immediate perturbation response considered here and that might damp its further development, some insight into the effects of ice dynamics can be gained from the work of Oerlemans and van der Veen [1984, pp. 106 and 191], who include a feedback effect of basal melting on basal sliding in two of their numerical models of ice sheet behavior. For the effect of basal melting on ice velocity they assume $v=b_{0}+b_{1} W$, with constant $b_{0}$ and $b_{1}$. It appears from their equation (6.4.1), by comparison with (18) above, that they implicitly assume $W=a_{0}+a_{1} P_{\mathrm{W}}$ (constant $a_{\mathrm{o}}$ and $a_{1}$ ). Hence they in effect assume $v=c_{0}+c_{1} P_{\mathrm{W}}$ (constant $c_{\mathrm{o}}$ and $c_{1}$ ), which for perturbations in $P_{\mathbf{w}}$ can approximately represent a nonlinear relation, as in (11) above. In one model they take $b_{0}=0$ and in the other $b_{0} \neq 0$, but since $a_{\mathrm{o}}$ is not necessarily 0 , both models may be based in effect on nonlinear $v$ versus $P_{\mathrm{W}}$ relations. Not enough information is given to deduce the effective $n$ used in either type of model. The $b_{0} \neq 0$ model shows bounded instability associated with multiple steady states, and the $b_{0}=0$ model shows oscillatory behavior for large enough values of $b_{1}$, which seems to represent a more complex type of bounded instability. The models thus indicate that instability can arise from a sensitive enough dependence of ice flow on basal water pressure, even when the possibly stabilizing effects of ice dynamics are included in the analysis. However, the possible influence of nonlinearity of the $v$ versus $P_{\mathrm{W}}$ relation on the stability-instability condition cannot be determined from the results, for the reason given above. Other differences between these models and the treatment here further limit the comparison: for example, the effective $\boldsymbol{\kappa}$ is either assumed constant or proportional to $\hat{P}$, and the water storage calculated in the models is 0.6 to $1.5 \mathrm{~m}$, much greater than the $W-1 \mathrm{~mm}$ considered reasonable here. For parameters that seem appropriate to these models $(W \sim 1 \mathrm{~m}$, $\tau_{\mathrm{B}} \sim 0.5$ bar, $v \sim 10 \mathrm{~m} \mathrm{y}^{-1}$ ), the time constant $H W / v \tau_{\mathrm{B}}$ in (32) is -600 years; this makes it possible that the early, accelerating part of the oscillations calculated by Oerlemans and van der Veen [1984, Figure 11.13], which takes place on a comparable time scale, is a manifestation of the type of "immediate" instability treated here.

The critical value of $n$, above which the deforming bed flow mechanism is unstable for the water layer conduit model, cannot be closely fixed, partly because the physical model and mathematical treatment are only approximate, but primarily because our knowledge of system parameters for the ice streams is limited. Particularly uncertain is the parameter $q$. The theoretical $q$ values of 1 and $\sim 12$ for two well-defined models of nonuniform water layer conduits leave a rather wide range of uncertainty as to what $q$ value is appropriate to the real system, if (13) is applicable. The critical value of $n$ depends strongly also on the wavelength of the perturbation that initiates the instability, according to (33), but we have no firm basis for choosing a value for this wavelength. Nevertheless, from the evaluation of the last section it appears that for reasonable choices of parameter values, the critical $n$ is likely to lie in the range from about 5 to 20 . This means that it makes a great difference for the functioning of the deforming bed mechanism whether basal till has flow properties like those assumed in current numerical modeling ( $n \leq 1.3$ ) or instead like those that appear appropriate from the work in soil mechanics discussed in the first section (n-15-100). It seems reasonably certain that a deforming bed mechanism in which the till rheology controls the rate of glacier motion is unstable if the till behaves mechanically like clay-rich soil at residual strength, with $n>\sim 100$, and if (13) applies.

Unless a mechanism for preventing perturbations of wavelength longer than about $10 \mathrm{~km}$ were in operation, a flow system subject to the above instability could not persist in its unstable steady state over geologic time. Are the fast-moving ice streams as we see them today the result of past speed-ups promoted by this instability? The form of the instability criterion in (32) permits this, because the datum-state ice stream velocity $v$ does not affect the condition of stability or instability (sign of $\$ \sigma \sigma$ ), although it does affect the time scale of its development. But by the same token, the present-day ice streams should still be unstable. Some type of instability in ice stream motion may be suggested by the recent stopping of Ice Stream C [Whillans and Bolzan, 1987], but no manifestation of instability in terms of rapid increase in ice stream velocities is currently observed.

From the seemingly stabilized motion of the currently active ice streams one is thus nudged to the conclusion that their motion is not now being controlled by till rheology, which, as the foregoing considerations indicate, would not provide stabilization. The implication is that some other mechanism limits the speed of motion.

An independent indication of the same conclusion is the low measured shear strength of the basal till, 0.02 bar from Figures 1 and 2, which makes the till an order of magnitude too weak to support the basal shear stress of 0.2 bar required mechanically as a regional average.

If an incipient ice stream (or an incipiently surging glacier) is subject to the deforming bed instability discussed above and begins to speed up rapidly because of it, the motion may become limited by some other resisting mechanism(s) at the bed before there is time for major adjustments in ice sheet configuration of the type modeled by Oerlemans and van der Veen [1984]. Such a course of events would be analogous to the theory of glacier surging by Lliboutry [1968, p. 51; 1969, p. 946], in which the sliding rate increases unstably because of basal cavitation over short-wavelength roughness elements, but the increase is ultimately stabilized by the sliding resistance of long-wavelength roughness elements. In the ice streams the stabilization could for example be achieved by the sliding resistance of scattered "sticky spots" of bedrock protruding through the basal till layer.

If the conclusion that some other mechanism controls the ice stream motions is correct, current attempts to model the ice stream motions on the assumption that they are controlled by the deforming bed mechanism are misdirected. Valid modeling of the ice stream motions can of course be done only when the mechanism that controls the motion has been securely identified and quantitatively formulated. The need for further effort in that direction is emphasized by the considerations here as to flow law nonlinearity in relation to stability/instability of the deforming bed mechanism. 


\section{APPENDIX}

We consider here the effect of the $x$ variation of the coefficients $D, E$, and $F$ on the solutions of (25). A first approximation to the $x$ variation is obtained by expanding the coefficients in power series in $x$, and keeping the constant and linear terms. To do this we expand the variations of (26), (27), and (28) differentially:

$$
\begin{aligned}
& \frac{\delta D}{D}=\frac{\delta v}{v}-\frac{\delta W}{W} \\
& \frac{\delta E}{E}=\frac{\delta D}{D}+\frac{\delta L}{L} \\
& \frac{\delta F}{F}=\frac{\delta E}{E}+\frac{\delta \hat{P}}{\hat{P}}
\end{aligned}
$$

The $\delta$ here designates differential changes from the values at an arbitrary point of interest (here taken at Upstream B), which will be designated $x=0$, so that $\delta L=\delta x=x$.

The longitudinal variation of $v$ represents longitudinal strain rate $e_{\mathbf{x x}}$ :

$$
\frac{\delta v}{v_{\mathrm{o}}}=\frac{\dot{e}_{\mathrm{xx}}}{v_{\mathrm{o}}} x-\frac{v_{\mathrm{o}}-v_{\mathrm{u}}}{v_{\mathrm{o}}} \frac{x}{L}
$$

Here $v_{\mathrm{u}}-100 \mathrm{~m} \mathrm{yr}^{-1}$ is the flow velocity at a point distant $L$ $-100 \mathrm{~km}$ upstream from the origin, where $\nu=v_{0}$; the last form of (38) assumes uniform longitudinal strain rate over this interval.

The variation of water storage $\delta W$ in (35) is linked to the variation in conductivity $\delta \mathrm{k}$ by (17) and thence to $x$ by (23) and (24):

$$
\frac{\delta W}{W}=\frac{\delta \kappa}{3 \kappa}=\frac{1}{3 \psi} \frac{x}{L}
$$

The variation of effective pressure $\Delta \hat{P}$ is linked to $\Delta W$ by (13) and thence to $x$ via (39)

$$
\frac{\delta \hat{P}}{\hat{P}}=-\frac{1}{q} \frac{\delta W}{W}=-\frac{1}{3 \psi q} \frac{x}{L}
$$

When (38)-(40) are combined in (35)-(37) and numerical values $\psi \sim 0.5$ and $q-3$ introduced (as used in the evaluation in the main text), the variations become

$$
\frac{\delta D}{D} \sim 0, \quad \frac{\delta E}{E} \sim \frac{x}{L}, \quad \frac{\delta F}{F} \sim \frac{x}{L}
$$

In (41), the variations have been rounded for simplicity to the nearest integral multiple of $x / L$, but this is not essential in the treatment that follows.

On the basis of (41), the first approximation to the $x$ variation is incorporated into (25) as follows:

$$
\frac{\partial \Pi}{\partial t}=D \Pi-E(1+\epsilon x) \frac{\partial \Pi}{\partial x}+F(1+\epsilon x) \frac{\partial^{2} \Pi}{\partial x^{2}}
$$

where for compactness $I$ is written for $\Delta P_{\mathrm{W}}$, where $\epsilon=1 / L$, and where $D, E$, and $F$ are now constants. To solve (42), a separation of variables is carried out in the usual way, with separation constant $\sigma$; the result is

$$
\begin{gathered}
\Pi(x, t)=e^{\sigma t}(x) \\
F(1+\epsilon x) \frac{d^{2}}{d x^{2}}-E(1+\epsilon x) \frac{d \Phi}{d x}+(D-\sigma) \Phi=0
\end{gathered}
$$

A differential equation of type (44) can in principle be solved exactly with confluent hypergeometric functions [Bateman Manuscript Project, 1953, p. 249], but to obtain a practical solution I use instead a perturbation method, based on the small value of $\epsilon x$ over an interval of adequate size around the point of interest. Let the solution of (44) be represented as

$$
\Phi=a e^{i k x}(1+\epsilon f(x))
$$

in which $f(x)$ is an undetermined function and $k=2 \pi / \lambda$. Introduce (45) into (44), take $\sigma$ as given in (30), and neglect terms in $\epsilon^{2}$. The result is

$$
\epsilon\left[F f^{\prime \prime}-(E-2 F k i) f^{\prime}-\left(F k^{2}+E k i\right) x\right]=0
$$

where primes denote differentiation. (46) is satisfied by

$$
f=r x^{2}+s x+p
$$

when the constants $r$ and $s$ are

$$
\begin{gathered}
2 r=-\left(F k^{2}+E k i\right) /(E-2 F k i) \\
s=2 r F /(E-2 F k i)
\end{gathered}
$$

The constant $p$, which is a solution of the homogeneous equation associated with (46), can be chosen so as to minimize $f(x)$ in some sense, for example, so as to make $f(x)$ average to zero over an interval of interest $-l \leq x \leq l$ :

$$
f=r x^{2}+s x-1 / 3 r l^{2}
$$

In the spirit of seeking a perturbation solution that deviates little from the sinusoidal perturbation in (31), we do not prescribe rigid initial and boundary conditions; rather, we seek to minimize $f(x)$. A second solution of the homogeneous equation could be added to (47), but minimization of $f(x)$ is best achieved without it. Measures of the departure of $f(x)$ from 0 are $f( \pm l)=2 / s \cdot l^{2} \pm s l$.

From the form of (43), (45), and (50) we see that the $x$ variation of the coefficients $D, E$, and $F$ in (25) affects the $x$ dependence of the solution, through nonzero $f(x)$ in (45), while leaving unchanged the exponential $t$ dependence in (31) and (43), with exponential coefficient $\sigma$ given by (30). Thus an initial perturbation $\Delta P_{\mathrm{W}}(x, 0)$ of the form (45) with $f(x)$ given by (48)-(50) will decay or grow exponentially with time, depending on the sign of $\Re \sigma$ as in (31).

The perturbation, instead of a simple sinusoid, has the form of a sinusoid with amplitude and phase varying slowly with $x$. Measures of the departure of the amplitude from that of a simple sinusoid over the interval $\sim l \leq x \leq l$ are $|1+\epsilon f( \pm l)|-1$. Evaluated with $l=10 \mathrm{~km}$ and the parameters used in the main text, for which $r=0.052-0.279 i$ $\mathrm{km}^{-1}, s=0.094-0.148 i$ (from (48) and (49) with parameter values via (26)-(28)), these measures are 0.033 and 0.011 , thus 
about 3\% maximum. The assumption, for stability analysis, of a sinusoidal perturbation is of course an arbitrary choice adapted to the form of the solution (29). It is therefore equally reasonable to assume an initial perturbation of the form (45), especially when this perturbation differs only slightly (3\% in amplitude, as shown above) from a sinusoidal perturbation over an $x$ interval of length $2 l \approx \lambda$. Thus the form of (43) justifies using the instability criterion (32) when $D, E$, and $F$ are slowly varying functions of $x$.

Acknowledgments. The Antarctic field work upon which some of this paper is based was supported by the National Science Foundation (grant DPP-8519083). The experimental work giving the results in Figure 2 was done by Hermann Engelhardt. I thank Ronald F. Scott for access to the facilities of the Caltech Soil Mechanics Library Charles Bentley made helpful comments on the manuscript. Caltech Division of Geological and Planetary Sciences, Contribution 4914.

\section{REFERENCES}

Aley, R.B., Water-pressure coupling of sliding and bed deformation: I. Water system, J. Glaciol., 35, 108-118, $1989 a$.

Alley, R.B., Water-pressure coupling of sliding and bed deformation: II. Velocity-depth profiles, J. Glaciol., 35, 119-129, $1989 b$.

Alley, R.B., D.D. Blankenship, C.R. Bentley, and S.T. Rooney, Till beneath Ice Stream B, 3, Till deformation: Evidence and implications, J. Geophys. Res., 92, 8921-8929, $1987 a$.

Alley, R.B., D.D. Blankenship, S.T. Rooney, and C.R. Bentley, Till beneath Ice Stream B, 4, A coupled ice-till flow model, J. Geophys. Res., 92, 8931-8940, $1987 b$.

Alley, R.B., D.D. Blankenship, S.T. Rooney, and C.R. Bentley, Water-pressure coupling of sliding and bed deformation. III. Application to Ice Stream B, J. Glaciol., 35, 131-139, 1989.

Bateman Manuscript Project, Higher Transcendental Functions, Vol. I, McGraw-Hill, New York, 1953.

Bentley, C.R., Antarctic ice streams: A review, J. Geophys. Res., 92, 8843-8858, 1987.

Biegel, R.L., C.G. Sammis, and J. Dieterich, Frictional properties of simulated gouge having a fractal particle size distribution, J. Struct. Geol., 11, 827-846, 1989.

Bindschadler, R., The importance of pressurized subglacial water in separation and sliding at the glacier bed, $J$. Glaciol., 29, 3-19, 1983.

Bindschadler, R.A., SeaRISE: a multidisciplinary research initiative to predict rapid changes in global sea level caused by collapse of marine ice sheets, NASA Conference Publication Preprint, Goddard Space Flight Center, Greenbelt, MD, 1990.

Bishop, A.W., G.E. Green, V.K. Garga, A. Andresen, and J.D. Brown, A new ring shear apparatus and its application to the measurement of residual strength, Geotechnique, 21, 273-328, 1971.

Blankenship, D.D., C.R. Bentley, S.T. Rooney, and R.B. Alley, Till beneath Ice Stream B, 1, Properties derived from seismic travel times, J. Geophys. Res., 92, 8903-8911, 1987.

Blanpied, M.L., T.E. Tullis, and J.D. Weeks, Frictional behavior of granite at low and high sliding velocity, Geophys. Res. Lett., 14, 554-557, 1987.

Bolton, M., A Guide to Soil Mechanics, John Wiley, New York, 1979.

Borja, R.I., and Kavazanjian, A constitutive model for the stress-strain-time behavior of "wet" clays, Geotechnique, 35 , 283-298, 1985.

Boulton, G.S., A paradigm shift in glaciology?, Nature, 322, 18, 1986.

Boulton, G.S., and R.C.A. Hindmarsh, Sediment deformation beneath glaciers: Rheology and geological consequences, J. Geophys. Res., 92, 9059-9082, 1987.

Boulton, G.S., and A.S. Jones, Stability of temperate ice sheets resting on beds of deformable sediment, J. Glaciol., 24, 29. 43, 1979.

Boulton, G.S., G.D. Smith, A.S. Jones, and J. Newsome, Glacial geology and glaciology of the last mid-latitude ice sheets, Q. J. Geol. Soc. London, 142, 447-474, 1985.

Brown, N.E., B. Hallet, and D.B. Booth, Rapid soft bed sliding of the Puget glacial lobe, J. Geophys. Res., 92, 8985 8997, 1987.

Budd, W.F., A first simple model for periodically self-surging glaciers, J. Glaciol., 14, 3-21, 1975.

Budd, W.F., and B.J. McInnes, Periodic surging of the Antarctic ice sheet - an assessment by modelling, Hydrol. Sci. Bull., 24, 95-104, 1979.

Clarke, G.K.C., Fast glacier flow: Ice streams, surging, and tidewater glaciers, J. Geophys. Res., 92, 8835-8841, $1987 a$.

Clarke, G.KC., Subglacial till: A physical framework for its properties and processes, J. Geophys. Res., 92, 9023-9036, $1987 b$.

Clarke, G.K.C., V. Nitsen, and W.S.B. Paterson, Strain heating and creep instability in glaciers and ice sheets, Rev. Geophys. Space Phys., 15, 235-247, 1977.

Engelhardt, H., N. Humphrey, B. Kamb, and M. Fahnestock, Physical conditions at the base of a fast moving Antarctic ice stream, Science, 248, 57-59, 1990.

Feda, J., Interpretation of creep of soils by rate process theory, Geotechnique, 39, 667-677, 1989.

Hughes, T.J., West Antarctic ice streams, Rev. Geophys. Space Phys., 15, 1-46, 1977.

Humphrey, N.F., Coupling between water pressure and basal sliding in a linked cavity hydraulic system, Publ. 170, pp. 105-120, Int. Soc. Hydrol. Sci., Wallingford, United Kingdom, 1987.

Hutter, K., Theoretical Glaciology, D. Reidel, Norwell, MA, 1983.

Iverson, R.M., A constitutive equation for mass-movement behavior, J. Geol., 93, 143-160, 1985.

Iverson, R.M., Unsteady, nonuniform landslide motion: 1. Theoretical dynamics and the steady datum state, J. Geol., 94, 1-15, 1986.

Kamb, B., Glacier surge mechanism based on linked cavity configuration of the basal water conduit system, $J$. Geophys. Res., 92, 9083-9100, 1987.

Kamb, B., Is the Antarctic Ice Sheet disintegrating?, Eng. Sci. 53(3), 5-13, 1990.

Kamb, B., and H. Engelhardt, Waves of accelerated motion in a glacier approaching surge: the mini-surges of Variegated Glacier, Alaska, J. Glaciol., 33, 27-46, 1987.

Lambe, T.W., and R.V. Whitman, Soil Mechanics, John Wiley, New York, 1969.

Lingle, C.S., and T.J. Brown, A subglacial aquifer bed model and water pressure dependent basal sliding relationship for a West Antarctic ice stream, in The Dynamics of the West Antarctic Ice Sheet, edited by C.J. van der Veen and J. Oerlemans, pp. 249-285, D. Reidel, Norwell, MA, 1987. 
Lliboutry, L., General Theory of subglacial cavitation and sliding of temperate glaciers, J. Glaciol., 7, 21-58, 1968.

Lliboutry, L., Contribution à la théorie des ondes glaciaires, Can. J. Earth Sci, 6, 943-954, 1969.

Lliboutry, L., Realistic, yet simple bottom boundary conditions for glaciers and ice sheets, J. Geophys. Res., 92, 9101-9109, 1987.

MacAyeal, D.R., Large-scale ice flow over a viscous basal sediment: Theory and application to Ice Stream B, Antarctica, J. Geophys. Res., 94, 4071-4087, 1989.

Maksimovic, M., On the residual shearing strength of clays, Geotechnique, 39, 347-351, 1989.

Mitchell, J.K., R.G. Campanella, and A. Singh, Soil creep as a rate process, J. Soil Mech. Found. Div. Am. Soc. Civ. Eng., 94(SM-1), 231-253, 1968.

Nakase, $\mathbf{A}$, and T. Kamei, Influence of strain rate on undrained shear characteristics of $\mathrm{K}_{\mathrm{o}}$-consolidated cohesive soils, Soils Found., 26, 85-95, 1986.

Nye, J.F., The flow of glaciers and ice sheets as a problem in plasticity, Proc. $R$ Soc. London, Ser. A, A207, 554-572, 1951.

Oerlemans, J., and C.J. van der Veen, Ice Sheets and Climate, D. Reidel, Norwell, MA, 1984.

O'Reilly, M.P., S.F. Brown, and R.F. Overy, Viscous effects observed in tests on an anisotropically normally consolidated silty clay, Geotechnique, 39, 153-158, 1989.

Prapaharan, S., J.L. Chameau, and R.D. Holtz, Effect of strain rate on undrained strength derived from pressuremeter tests, Geotechnique, 39, 615-624, 1989.

Rothlisberger, $H_{\text {., }}$ Water pressure in intra- and subgalcial channels, J. Glaciol, 11, 177-203, 1972.

Scholz, C.H., The Mechanics of Earthquakes and Faulting, Cambridge University Press, New York, 1990.

Shabtaie, S., and C.R. Bentley, Ice-thickness map of the West Antarctic ice streams by radar sounding, Ann. Glaciol., 11, 126-136, 1988

Shabtaie, S., I.M. Whillans, and C.R. Bentley, The morphology of Ice Streams A, B, and C, West Antarctica, and their environs, J. Geophys. Res., 92, 8865-8883, 1987.
Shoemaker, E.M., Subglacial hydrology for an ice sheet resting on a deformable aquifer, J. Glaciol., 32, 20-30, 1986.

Singh, A, and J.K. Mitchell, A general stress-strain-time function for soils, J. Soil Mech. Found. Div. Am. Soc. Civ. Eng., 94(SM-1), 21-46, 1968.

Skempton, A.W., Residual strength of clays in landslides, folded strata, and the laboratory, Geotechnique, 35, 3-18, 1985.

Thomas, R.H., Ice sheet margins and ice shelves, in Climate Processes and Climate Sensitivity, Geophys. Monogr. Ser., Vol. 29, edited by J.E. Hansen and T. Takahashi, 265-274, AGU, Washington, DC, 1984.

Thomas, R.H., T.J.O. Sanderson, and K.E. Rose, Effect of climatic warming on the West Antarctic ice sheet, Nature, 277, 355-358, 1979.

Tullis, T.E., Rock friction and constitutive behavior from laboratory experiments and its implications for an earthquake prediction program, Pure Appl. Geophys., 126, 555-585, 1988.

van der Veen, C.J., The West Antarctic Ice Sheet: the need to understand its dynamics, in Dynanics of the West Antarctic Ice Sheet, edited by C.J. Van der Veen, and J. Oerlemans, pp. 1-16, D. Riedel, Norwell, MA, 1987.

Weertman, J., Water lubrication mechanism of glacier surges, Can. J. Earth Sci., 6, 929-942, 1969.

Weertman, J., General theory of water flow at the base of a glacier or ice sheet, Rev. Geophys. Space Phys., 10, 287-333, 1972.

Weertman, J., and G.E. Birchfield, Subglacial water flow under ice streams and West-Antarctic ice-sheet stability, Ann. Glaciol., 3, 316-320, 1982.

Whillans, I.M., and J. Bolzan, Velocity of Ice Streams B and C, Antarctica, J. Geophys. Res., 92, 8895-8902, 1987.

(Received September 20, 1990; revised March 4, 1991; accepted March 25, 1991.) 